\title{
The Fatigue Pictogram: Psychometric evaluation of a new clinical tool
}

by Margaret I. Fitch, Terry Bunston, Debra Bakker, Deborah Mings and Patricia Sevean

\section{Abstract}

Fatigue is one of the most prevalent side effects of cancer, yet clinicians may not focus on it during busy clinic appointments. The purpose of this project was to evaluate the psychometric properties of a new two-item instrument designed to quickly identify patients experiencing difficulties with fatigue. The evaluation was conducted with 190 lung cancer patients attending ambulatory clinics. The Fatigue Pictogram had good reliability for test-retest over a 24-hour period (Weighted Kappa 0.71 for Question 1 and 0.72 for Question 2) and for equivalence of method (in person versus phone) (Weighted Kappa 0.64 for Question 1 and 0.65 for Question 2). Validity was assessed by comparing results of the new tool against the Multidimensional Fatigue Inventory and the SF-36. Overall, patients who indicated high fatigue levels did so on all respective scales.

The new Fatigue Pictogram was easy to administer and score in a busy clinical setting. It provides a standardized reliable and valid instrument to identify patients experiencing difficulty with fatigue.

Fatigue is one of the most prevalent and distressing side effects of cancer. It is the only symptom reported by the majority of cancer patients in all diagnostic groups (Curt \& Johnson, 2003). It threatens quality of life and interferes with many activities of daily living (Ahlberg, Ekman, Gaston-Johansson, \& Mock, 2003). Unfortunately, fatigue is not often assessed systematically by health care providers leaving them somewhat unaware of the impact fatigue has upon patients (Davis, Lai, Hahn, \& Cella, 2008). Additionally, interventions are not routinely offered to help patients manage the fatigue or cope

\section{About the authors}

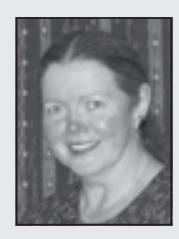

Margaret I. Fitch, RN, PhD, Head, Oncology Nursing, Co-director, Patient \& Family Support Program, Sunnybrook Odette Cancer Centre, 2075 Bayview Avenue, Toronto, ON M4N 3M5

Telephone: 416-480-5891, Fax: 416-480-7806, marg.fitch@sunnybrook.ca

Terry Bunston, MSW, PhD (deceased)

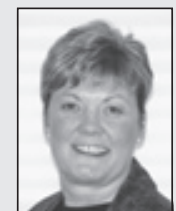

Debra Bakker, RN, PhD, Professor, School of Nursing, Laurentian University, 935 Ramsey Lake Road, Sudbury, ON P3E 2C6

Tel: 705-675-1151 ext. 3837, Fax: 705-675-4861, dbakker@laurentian.ca

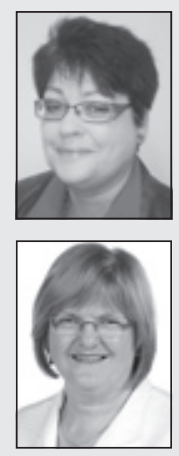

Deborah Mings, RN, MHSc, GNC(C), IIWCC, 6-3010 Palmer Drive, Burlington, ON L7M 1 L2

905-527-4322 ext.46877, dmings@bellnet.ca

Pat Sevean, RN, MA(N), Associate Professor, School of Nursing, Lakehead University, 955 Oliver Road, Thunder Bay, ON P7B 5E1

Telephone: 807-343-8396, Fax: 807-343-8246, psevean@lakeheadu.ca with its impact, despite the fact there is a growing body of evidence about fatigue interventions. Practice guidelines from the National Comprehensive Cancer Network (NCCN) indicate that a systematic approach is required to screen, assess, and manage fatigue appropriately (NCCN, 2007).

Busy clinical settings, heavy patient caseloads, and lack of easily applied instruments to identify patients who are experiencing fatigue are cited as reasons why the side effect is not routinely assessed during a clinical consultation. The Fatigue Coalition (Vogelzang, Breitbart, Cella, Curt, Groopman, Herning, et al., 1997) reported nearly one-third of the patients who had fatigue mentioned it to their physician on every visit to the office while only $6 \%$ of their physicians believed that it was mentioned that frequently. Fatigue was cited as a primary patient concern by patients within lung (Fitch \& Steele, 2010), advanced disease (Fitch, 2010), gynecologic (Steele \& Fitch, 2008), and breast cancer (Fitch, Gowing, Murray, McKillop, Schertzer, \& Deane, 2002) populations.

The need for an easily administered and scored instrument to measure fatigue led us to design a new tool for quick clinical screening of fatigue in busy clinical environments. With a psychometrically sound instrument, patients can be triaged efficiently for concerns about fatigue and referred appropriately. The instrument can serve both as a trigger to health care professionals to pay attention to fatigue and as an aid for easy documentation and regular monitoring of the symptom over time.

\section{Background}

Although there is no one universally accepted definition of fatigue (Tiesinga, Dassen, \& Halfens, 1996), there are common threads running through the existing definitions. These include notions that fatigue is subjective and multidimensional (Irvine, Vincent, Grayson, Bubela, \& Thompson, 1994; Winningham, Nail, Burke, Brophy, Cimprich, Jones, et al., 1994), has different modes of expression (Smets, Garssen, Cull, \& deHaes, 1996), exists along a continuum, and involves energy depletion (Irvine et al., 1994). In cancer, fatigue is frequently defined as a condition characterized by subjective feelings of tiredness; loss of strength; and endurance or energy that varies in degree, frequency, and duration with different modes of expression (i.e., physical, functional, cognitive, emotional, social and motivational) (Ahlberg, Ekman, Gaston-Johansson, \& Mock, 2003; Olson, 2007).

The prevalence of fatigue has been well documented. Estimates of fatigue during chemotherapy range from $70 \%$ to $100 \%$ (AncoliIsrael, Liu, Marler, Parker, Jones, Sadler, et al., 2006) while those in radiation range from 80\% to 100\% (Danjoux, Gardner \& Fitch, 2007). Fatigue has been documented as seven times more prevalent in the cancer population than in the general population (Cella, Lai, Chang, Peterman, \& Slavin, 2002) and qualitatively different. For cancer patients, fatigue is rarely relieved by rest or sleep (Olson, Krawchuk, \& Qudussi, 2007).

The severity of fatigue in cancer ranges from mild to moderate and severe, but is not directly related to type of cancer, cancer stage, size of tumor, number of nodes or the presence or site of metastases (Servaes, Verhagen, \& Bleijenberg, 2002). Winningham et al. (1994) stated that the pattern of fatigue over the illness and treatment regimen varies with disease type, site and regimen. For many, fatigue tends to increase over the course of treatment and dissipates once treatment has finished (Irvine et al., 1994). However, for some patients fatigue has been reported to persist after the treatment has finished, sometimes for several years (Berglund, 
Bolund, Fornander, Rutqvist, \& Sjoden, 1991). Qualitative studies have emphasized the uniqueness of each patient's experience and have focused on the impact of cancer-related fatigue (Chan \& Molassiotis, 2001). Fatigue becomes significant when it reaches a level where it adversely affects an individual's quality of life (Wei, Dunn, Sandler, McLaughlin, Montie, Litwin, et al., 2002). Fatigue can interfere with employment, leisure and social activities, and activities of daily living.

Clinical assessment of fatigue helps to link interventions to the underlying etiology. Changes in the patients' drug regimen, reversal of anemia or metabolic abnormalities, or treatment of sleep disorders or depression are potential avenues for intervention (Portenoy \& Itri, 1999). Psychostimulants (e.g., methylphenidate, pemoline and dextroamphetamine) and selective serotonin-reuptake inhibitors are being used empirically to counteract debilitating fatigue (Cleeland, 2001). The nonpharmacologic approaches for the management of cancer-related fatigue are receiving more attention and are showing benefits for some patients. These include walking or exercise programs (Windsor, Nicol, \& Poller, 2004) educating patients about fatigue (Ream, Richardson, \& Alexander-Dann, 2006), and individual counselling by professionals (Mitchell, Beck, Hood, Moore, \& Tanner, 2007).

Over the years, several instruments have been developed to measure fatigue from the cancer patient's perspective across its several dimensions (Smets, Garssen, Cull, \& deHaes, 1996; Cella, 1997; Wu \& McSweeney, 2004; Yellen, Cella, Webster, Blendowski, \& Kaplan, 1997). Piper's scale is one of the most popular and measures fatigue using the characteristics of temporal, intensity, affective, sensory evaluative, associated symptoms, and relief patterns (Piper, 1990). However, these tools were originally developed as research instruments and not as screening tools. Their length and complexity preclude easy administration and interpretation within a busy clinical setting. What is needed is a brief, psychometrically sound, easily administered and scored device where results could be readily available for clinical decision-making.

In response to the need for a clinically appropriate tool to measure fatigue we designed an instrument called the Fatigue Pictogram. It was created to measure the two dimensions of fatigue most frequently described by patients (i.e., how tired they feel and how much they are not able to do within their daily activities). It was designed as a screening or triage device with two items. The patients who are identified as experiencing difficulties with fatigue using the short instrument can then undergo an in-depth assessment of fatigue and receive appropriate interventions.

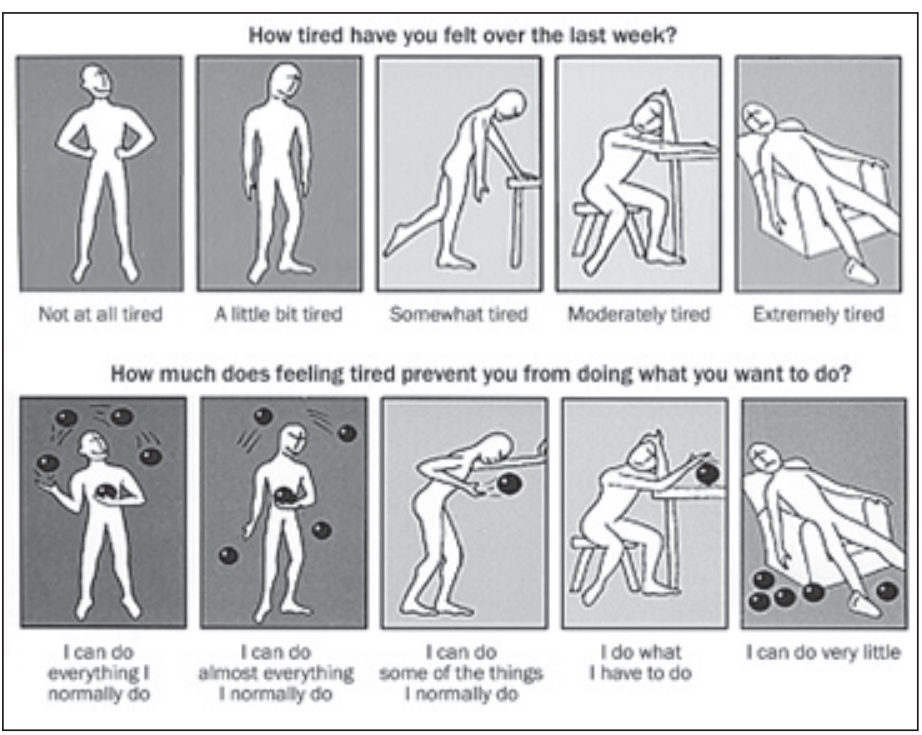

Figure 1. The Fatigue Pictogram

\section{Purpose}

This paper will report on the psychometric evaluation of the newly developed fatigue instrument. The evaluation was conducted with lung cancer patients attending a multidisciplinary outpatient clinic. Assessing the psychometric properties and performance of a new measurement device is important if appropriate clinical decisions are to be made on the basis of the data provided by the tool. In this study, reliability and validity will be reported, as well as the performance in correctly categorizing or identifying patients with clinically significant fatigue. Reliability is defined as the extent to which an instrument yields the same results (consistency) on repeated measures (Nunnally \& Bernstein, 1994). Both consistency over time (test-retest) and over method (telephone and in person) were considered relevant in this case. Validity refers to whether an instrument accurately measures what it is supposed to measure (Nunnally \& Bernstein, 1994). Assessment against standard validated fatigue and quality of life measures were seen as appropriate for this work to determine concurrent and construct validity.

\section{Methods}

The study protocols were submitted to and approved by the ethics review boards of the four cancer centres from which patients were drawn. Accrual occurred in the reception area of the ambulatory clinic while patients waited for their appointments. The study coordinator assessed patients for eligibility together with the clinic nurse according to the following criteria: a definitive diagnosis of cancer, 18 years of age or older, able to speak English, and not experiencing current mental illness or high emotional distress. The coordinator approached eligible patients, explained the study requirements, and invited their participation. Those who consented to participate completed an informed consent document and began the first round of data collection while in the clinic setting. A package of data collection materials was provided for the participating individuals to take home with them and use in the subsequent interactions with the study coordinator over the telephone.

Participation: Study participation involved completing the data collection instruments on four occasions. The patient completed the instruments in the waiting room of the lung cancer clinic the first time (Time 1) during a face-to-face interaction with the study coordinator. The rest of the data collection was conducted over the telephone according to the following schedule: Time 2 occurred 24 hours after Time 1, Time 3 occurred 24 hours after Time 2, and Time 4 occurred seven days later. This data collection schedule allowed us to determine reliability or consistency between two methods (i.e., face-to-face and over the telephone), as well as over a short interval (i.e., 24 hours over the phone). The 24-hour time interval was selected as a short time frame in which one would not expect actual change in the level of fatigue. The weeklong interval, when change in fatigue levels would be expected, allowed for determination of sensitivity to change over time (i.e., one week over the phone). Application of standardized fatigue and quality of life scales allowed the determination of validity.

Data collection instrumentation: The data collection tools included a demographic data sheet, the newly developed Fatigue Pictogram, and two validated standardized tools - the Multidimensional Fatigue Inventory (Smets, et al., 1996), and the SF-36 (Ware, 1992), as a measure of quality of life. The demographic sheet was created for this study and gathered age, gender, education, marital status, time since diagnosis, and performance status. Performance status was measured using the Eastern Cooperative Oncology Group rating (ECOG) (Zubrod, Schneiderman, Frei, Brindley, Gold, Snider, et al., 1960).

The Fatigue Pictogram was developed as an easily administered and scored tool for measuring fatigue in a clinical setting. There are two questions or items measuring the dimensions patients talk most 
frequently about when describing their fatigue. Question 1 asks, "How tired have you felt over the last week?" and elicits responses on a five-point Likert scale ranging from "not at all' (scored as 0) to " extremely tired" (scored as 4). Question 2 asks, "How much does feeling tired prevent you from doing what you want to do?" Responses range from "I can do everything I normally do" to "I can do very little" and are scored from 0 to 4 . Each response option is depicted in a picture with a generic figure and an appropriate colour (See Figure 1). Words are written under each of the pictures as well, but no numbers are evident to the patients completing the tool. The Fatigue Pictogram is formatted on a laminated card with one question on either side. The card can be carried easily in a uniform or lab coat pocket and shown to patients in the clinical setting. The response can be charted in the patient record in numerical form and easily tracked over time.

The Multidimensional Fatigue Inventory (MFI) (Smets et al., 1996) was developed for use with cancer patients. It is a 20-item instrument that measures five dimensions of fatigue: general, physical, mental, reduced motivation, and reduced activity. A factor analysis supported the five dimensions and, in cancer populations, Cronbach's alphas for the subscales ranged from 0.77 to 0.86 . The instrument has been shown to have construct and convergent validity.

The SF-36 (Ware, 1992) is a well-established generic measure of quality of life. It consists of eight subscales: physical functioning, role-physical, bodily pain, general health vitality, social function-

Table 1. Distribution of responses for the Fatigue Pictogram (FP) for lung cancer patients and ECOG performance status

\begin{tabular}{|l|l|l|l|l|}
\hline \multirow{4}{*}{ Items } & \multicolumn{4}{|c|}{ Proportion of Responses } \\
\cline { 2 - 5 } & Time 1 & Time 2 & Time 3 & Time 4 \\
& $\mathrm{N}=190$ & $\mathrm{~N}=190$ & $\mathrm{~N}=176$ & $\mathrm{~N}=173$ \\
\hline
\end{tabular}

FP Q1: How tired have you felt over the past week?

\begin{tabular}{|l|c|c|c|c|}
\hline Not at all tired & 12.2 & 6.3 & 8.5 & 5.8 \\
\hline A little bit tired & 31.6 & 37.9 & 31.8 & 33.8 \\
\hline Somewhat tired & 25.8 & 24.4 & 30.7 & 27.2 \\
\hline Moderately tired & 16.9 & 17.4 & 18.2 & 24.0 \\
\hline Extremely tired & 13.7 & 11.1 & 10.8 & 9.0 \\
\hline
\end{tabular}

FP Q2: How much does feeling tired prevent you from doing what you want to do?

\begin{tabular}{|l|c|c|c|c|}
\hline I can do everything & 13.2 & 11.6 & 12.0 & 8.4 \\
\hline I can do almost everything & 29.5 & 29.5 & 28.4 & 27.2 \\
\hline I can do some things & 28.4 & 29.5 & 28.4 & 31.8 \\
\hline I do what I have to & 18.4 & 18.4 & 19.3 & 25.3 \\
\hline I can do very little & 10.5 & 11.1 & 11.4 & 7.1 \\
\hline ECOG: Normal activity & 37.9 & 35.2 & 37.6 & 33.1 \\
\hline Symptoms & 37.9 & 39.6 & 35.8 & 45.0 \\
\hline Some time in bed $(<50 \%)$ & 20.3 & 20.9 & 23.2 & 16.1 \\
\hline Needs to be in bed $(>50 \%)$ & 3.3 & 4.3 & 3.5 & 5.3 \\
\hline Unable to get out of bed & 0.5 & - & - & - \\
\hline \multicolumn{5}{|l|l|}{} \\
\hline
\end{tabular}

ing, role-emotional, and mental health. The SF-36 has been tested extensively and used in a number of populations with chronic illness including cancer.

Statistical analysis: The SAS statistical software version 9.1.3. (SAS Institute Inc., Cary, North Carolina) was used for data analysis. The raw data were summarized and descriptive statistics were calculated for all demographic data and for item and total and subscale scores. Reliability was assessed using the Weighted Kappa Statistic because of the ordinal nature of the Fatigue Pictogram and the desire to measure agreement between scorers in classifying observations into categories. Equivalence of method was tested using Time 1 and Time 2 data; test-retest reliability was tested using Time 2 and Time 3 data; and sensitivity was tested using Time 3 and Time 4 data. Concurrent validity was assessed by comparing the responses for each of the Fatigue Pictogram questions against the subscale total scores of the Multidimensional Fatigue Inventory. We expected that individuals who had high scores on the Fatigue Pictogram would also have high scores on the three relevant sub-

Table 2. Mean scores for MFI and SF-36 across T1-T4 for lung cancer patients

\begin{tabular}{|c|c|c|c|c|}
\hline $\begin{array}{l}\text { Multidimensional Fatigue } \\
\text { inventory (subscales + total) }\end{array}$ & Time 1 & Time 2 & Time 3 & Time 4 \\
\hline General & $\begin{array}{c}17.61 \\
(6.3)\end{array}$ & $\begin{array}{l}16.95 \\
(6.4)\end{array}$ & $\begin{array}{l}16.98 \\
(6.3)\end{array}$ & $\begin{array}{c}17.25 \\
(6.3)\end{array}$ \\
\hline Physical & $\begin{array}{l}17.89 \\
(6.8)\end{array}$ & $\begin{array}{l}17.50 \\
(6.4)\end{array}$ & $\begin{array}{c}17.72 \\
(6.6)\end{array}$ & $\begin{array}{c}17.91 \\
(6.3)\end{array}$ \\
\hline Mental & $\begin{array}{c}11.31 \\
(6.2)\end{array}$ & $\begin{array}{l}11.27 \\
(6.0)\end{array}$ & $\begin{array}{c}11.31 \\
(6.5)\end{array}$ & $\begin{array}{c}11.52 \\
(6.3)\end{array}$ \\
\hline Reduced motivation & $\begin{array}{l}12.5 \\
(5.5)\end{array}$ & $\begin{array}{c}12.52 \\
(5.7)\end{array}$ & $\begin{array}{l}12.94 \\
(5.9)\end{array}$ & $\begin{array}{l}13.09 \\
(5.4)\end{array}$ \\
\hline Reduced activities & $\begin{array}{c}16.43 \\
(6.9)\end{array}$ & $\begin{array}{l}16.58 \\
(7.0)\end{array}$ & $\begin{array}{c}16.82 \\
(7.1)\end{array}$ & $\begin{array}{c}16.84 \\
(6.9)\end{array}$ \\
\hline TOTAL & $\begin{array}{c}75.7 \\
(26.2)\end{array}$ & $\begin{array}{c}74.8 \\
(25.9)\end{array}$ & $\begin{array}{c}75.9 \\
(26.7)\end{array}$ & $\begin{array}{c}76.9 \\
(26.2)\end{array}$ \\
\hline SF-36 Subscales & Time 1 & Time 2 & Time 3 & Time 4 \\
\hline Physical-functioning & $\begin{array}{l}21.1 \\
(5.2)\end{array}$ & $\begin{array}{l}21.0 \\
(4.9)\end{array}$ & $\begin{array}{l}20.9 \\
(5.2)\end{array}$ & $\begin{array}{l}20.6 \\
(5.0)\end{array}$ \\
\hline Role-physical & $\begin{array}{c}5.5 \\
(1.6)\end{array}$ & $\begin{array}{c}5.3 \\
(1.5)\end{array}$ & $\begin{array}{c}5.3 \\
(1.5)\end{array}$ & $\begin{array}{c}5.4 \\
(1.6)\end{array}$ \\
\hline Bodily pain & $\begin{array}{c}8.1 \\
(7.6)\end{array}$ & $\begin{array}{c}8.2 \\
(2.6)\end{array}$ & $\begin{array}{c}8.0 \\
(2.7)\end{array}$ & $\begin{array}{c}8.3 \\
(2.5)\end{array}$ \\
\hline General health & $\begin{array}{l}15.1 \\
(4.5)\end{array}$ & $\begin{array}{l}14.6 \\
(4.7)\end{array}$ & $\begin{array}{l}14.4 \\
(4.5)\end{array}$ & $\begin{array}{l}14.6 \\
(4.7)\end{array}$ \\
\hline Vitality & $\begin{array}{l}13.0 \\
(4.8) \\
\end{array}$ & $\begin{array}{l}13.3 \\
(4.9) \\
\end{array}$ & $\begin{array}{l}13.4 \\
(4.8) \\
\end{array}$ & $\begin{array}{l}13.2 \\
(4.9) \\
\end{array}$ \\
\hline Social functioning & $\begin{array}{c}7.2 \\
(2.4)\end{array}$ & $\begin{array}{c}7.1 \\
(2.3)\end{array}$ & $\begin{array}{c}7.1 \\
(2.3)\end{array}$ & $\begin{array}{c}7.1 \\
(2.4)\end{array}$ \\
\hline Role-emotional & $\begin{array}{c}5.1 \\
(1.2)\end{array}$ & $\begin{array}{c}4.9 \\
(1.2)\end{array}$ & $\begin{array}{c}4.9 \\
(1.3)\end{array}$ & $\begin{array}{c}5.0 \\
(1.2)\end{array}$ \\
\hline Mental & $\begin{array}{l}23.4 \\
(4.4)\end{array}$ & $\begin{array}{l}23.6 \\
(4.3)\end{array}$ & $\begin{array}{l}23.7 \\
(4.1)\end{array}$ & $\begin{array}{l}30.0 \\
(4.2)\end{array}$ \\
\hline Reported health transitions & $\begin{array}{c}3.5 \\
(1.3)\end{array}$ & $\begin{array}{c}3.4 \\
(1.3)\end{array}$ & $\begin{array}{c}3.4 \\
(1.3)\end{array}$ & $\begin{array}{c}3.3 \\
(1.3)\end{array}$ \\
\hline
\end{tabular}


scales of the Multidimensional Fatigue Inventory (i.e., general, physical, reduced activity). Construct validity was assessed by comparing the responses of the Fatigue Pictogram against the subscale total scores of the SF-36. We expected that individuals who had high scores on the Fatigue Pictogram would have low scores on the four corresponding quality of life subscales of the SF-36 (i.e., physical functioning, role-physical, vitality, and social functioning).

\section{Results}

\section{Selected sample characteristics}

A mixed sample of 190 lung cancer patients attending ambulatory multidisciplinary lung clinics participated in this psychometric evaluation. Approximately equal numbers of men (53.2\% of sample) and women (46.8\% of sample) completed the data collection instruments. The average age of the participants was $61.4(\mathrm{SD}=11.0)$ years at the time of the cancer diagnosis and $63.0(\mathrm{SD}=11.1)$ at the time of their participation in the study. Sixty-one per cent were married and about a third of the sample (34.3\%) had completed college/university education. A quarter (25.8\%) had less than high school education. The majority were on active treatment.

\begin{tabular}{|c|c|c|c|c|}
\hline Pictogram Item & Analysis & $\begin{array}{l}\text { Time } 1 \\
\text { and Time } \\
2 \text { (face to } \\
\text { face and } \\
\text { over the } \\
\text { phone } \\
24 \text { hours } \\
\text { apart) }\end{array}$ & $\begin{array}{l}\text { Time } \\
2 \text { and } \\
\text { Time } 3 \\
\text { (over the } \\
\text { phone } \\
24 \text { hours } \\
\text { apart) }\end{array}$ & $\begin{array}{l}\text { Time } 3 \\
\text { and Time } \\
4 \text { (over } \\
\text { the phone } \\
7 \text { days } \\
\text { apart) }\end{array}$ \\
\hline \multirow{2}{*}{$\begin{array}{l}\text { Question } 1 \\
\text { How tired have } \\
\text { you felt over the } \\
\text { past week? }\end{array}$} & $\begin{array}{l}\text { Weighted } \\
\text { Kappa** }\end{array}$ & 0.71 & 0.64 & 0.54 \\
\hline & $\%$ Agreement & $69.3 \%$ & $59.5 \%$ & $58.4 \%$ \\
\hline \multirow{2}{*}{$\begin{array}{l}\text { Question } 2 \\
\text { How much does } \\
\text { feeling tired } \\
\text { prevent you } \\
\text { from doing what } \\
\text { you want to do? }\end{array}$} & $\begin{array}{l}\text { Weighted } \\
\text { Kappa* }\end{array}$ & 0.72 & 0.65 & 0.45 \\
\hline & $\%$ Agreement & $69.3 \%$ & $60.5 \%$ & $51.9 \%$ \\
\hline
\end{tabular}

Distribution of performance status,

fatigue and quality-of-life scores

The ECOG scores showed a range in performance status at all four measurement points (see Table 1) from normal activity to being in bed more than $50 \%$ of the time. Responses to the Fatigue Pictogram Question 1 (i.e., how tired the person had felt over the past week) and Question 2 (i.e., how much feeling tired prevented the person doing what they wanted to do) also revealed a range of perspectives (see Table 1). The proportion of responses indicating greater fatigue increased from Time 1 to Time 4.

The scores on both the MFI and SF-36 showed a range of perspectives, as well (see Table 2). Mean total scores on the MFI showed a slight increase in fatigue over time while mean scores for the SF-36 subscales of physical functioning, general health, role-physical, and social functioning decreased slightly from Time 1 to Time 4 . None of the decreases was significant.

\section{Reliability of the Fatigue Pictogram}

Reliability of the Fatigue Pictogram was determined using the Weighted Kappa statistic. This analysis showed the level of agreement in responses between method types (face-to-face versus telephone) and time intervals (24 hours apart, seven days apart). As we anticipated, the highest level of agreement for both Question 1 and Question 2 on the Fatigue Pictogram was for the short 24 hours test-retest using the same method (i.e., over the telephone). The seven-day interval (sensitivity to change) showed the lowest level of agreement (see Table 3).

\section{Validity}

Concurrent validity was assessed using regression analysis to determine the level of agreement between the new tool and the previously validated measures. Table 4 presents the concurrent validity results over the four time periods between the new Fatigue Pictogram and the Multidimensional Fatigue Inventory total and subscale scores. Both Fatigue Pictogram questions and the Multidimensional Fatigue Inventory classified the same participants as being fatigued (i.e., participants who had high scores on one instrument also had high scores on the other). In particular, patients who had high scores on Question 1 of the Fatigue Pictogram about feeling tired also had high scores on the two corresponding subscales of the Multidimensional Fatigue Inventory (general, physical). Those who had high scores on Question 2 of the Fatigue Pictogram about not being able to engage in activities also had high scores on the reduced activity subscale of the MFI. In contrast, coefficients between the Fatigue Pictogram questions and the other Multidimensional Fatigue

Table 4. Agreement between Fatigue Pictogram (FP) questions and subscales of the Multidimensional Fatigue Inventory in lung cancer patients

\begin{tabular}{|c|c|c|c|c|c|c|c|c|c|}
\hline \multirow[t]{2}{*}{ MFI Subscales } & \multirow[t]{2}{*}{$\mathbf{N}$} & \multicolumn{4}{|c|}{$\begin{array}{l}R^{2} \text { Coefficients for FP-Question } 1 \\
\text { (How tired have you felt over the past week?) }\end{array}$} & \multicolumn{4}{|c|}{$\begin{array}{l}\mathrm{R}^{2} \text { Coefficients for } \mathrm{FP}-\text { Question } 2 \\
\text { (How much does feeling tired prevent } \\
\text { you from doing what you want to do?) }\end{array}$} \\
\hline & & $\mathrm{T} 1$ & $\mathrm{~T} 2$ & T3 & $\mathrm{T} 4$ & $\mathrm{~T} 1$ & $\mathrm{~T} 2$ & T3 & $\mathrm{T} 4$ \\
\hline General & 149 & 0.48 & 0.60 & 0.53 & 0.48 & 0.56 & 0.58 & 0.45 & 0.45 \\
\hline Physical & 148 & 0.38 & 0.43 & 0.48 & 0.41 & 0.55 & 0.50 & 0.50 & 0.49 \\
\hline Mental & 148 & 0.19 & 0.11 & 0.06 & 0.10 & 0.16 & 0.21 & 0.14 & 0.20 \\
\hline Reduced motivation & 147 & 0.19 & 0.27 & 0.29 & 0.26 & 0.31 & 0.31 & 0.34 & 0.38 \\
\hline Reduced activity & 147 & 0.27 & 0.37 & 0.41 & 0.35 & 0.48 & 0.46 & 0.47 & 0.47 \\
\hline Total scores & 147 & 0.45 & 0.50 & 0.50 & 0.43 & 0.59 & 0.60 & 0.56 & 0.55 \\
\hline
\end{tabular}


Inventory subscales (mental, reduced motivation) were lower, illustrating less agreement with these dimensions that were not measured by the Pictogram items (see Table 4).

Construct validity was assessed using regression analysis to explore the relationship between fatigue and quality of life. As we anticipated, patients who had high scores on the Fatigue Pictogram had scores indicating low quality of life on the corresponding subscales of the SF-36 (physical functioning, vitality, social functioning, role-physical) (see Table 5).

\section{Discussion}

The Fatigue Pictogram was designed to be an easily administered and scored measurement device for use in a busy clinical setting. It was designed to quickly and reliably triage which cancer patients had fatigue and required further assessment and intervention. This initial psychometric evaluation was undertaken to assess reliability and validity in a group of lung cancer patients.

The Fatigue Pictogram, with only two questions, was very easy to administer and score in a busy clinical setting. Patients had no difficulty indicating a response to the Fatigue Pictogram questions, even with limited English because of the pictures and colours. The scores were readily available to the clinical team and provided the basis for a conversation about fatigue with the patient. Our study findings showed each Fatigue Pictogram question was capable of capturing variation in fatigue perspectives. That fatigue was both present and existed to varying degrees in the study sample was confirmed by the ECOG scores.

The reliability coefficients indicated good consistency between methods of administration (face-to-face and over the telephone) and test-retest over the 24-hour period (same method-over the telephone). As we expected, the strongest agreement was observed for the same method (over the telephone) over a short time period (24 hours). This is the scenario with the least likelihood of actual change. Similarly, the lowest level of agreement for the sevenday period was anticipated because there is a greater likelihood a patient's level of fatigue has actually changed in that period of time. The lower level of agreement indicates that the fatigue pictogram captured the change in fatigue over the longer time period.

The validity results were also consistent with the anticipated or hypothesized directions. The Pictogram was designed as a screen- ing tool to measure only the dimensions of physical tiredness and activity levels, and the scores for the pictogram questions corresponded most strongly with the physical and activity subscales of the Multidimensional Fatigue Inventory and the SF-36. These results support the notion that the Fatigue Pictogram items accurately measure the physical dimension of fatigue and the related activity levels rather than other aspects of fatigue (i.e., mental) and are able to classify individuals accurately as fatigued, or experiencing reduced activity because of fatigue. It is appropriate for a screening tool to focus on prevalent dimensions (in this case, the ones that patients are most apt to talk about, physical and activity reduction) while leaving the other aspects for an in-depth assessment (emotional, cognitive. etc.).

Finally, construct validity can be claimed for the Fatigue Pictogram based on its performance related to the theoretical notion or hypothesis that heightened fatigue is associated with lower quality of life. This notion was supported in that high Fatigue Pictogram scores were associated with low quality-of-life scores on the relevant SF-36 subscales.

\section{Implications for practice and research}

Psychometric evaluation of a new measurement device is an important aspect of its development. Ensuring both reliability and validity provides assurance about the instrument's performance and instills confidence about making clinical decisions based on its scores. The results from this study support the use of the Fatigue Pictogram as an easily administered measurement device for quickly identifying if patients are experiencing fatigue. In this regard, the Fatigue Pictogram can be used with confidence by oncology nurses, as a screening device to classify individuals who are experiencing fatigue and could benefit from deeper assessment and potential intervention. It is important to acknowledge that this tool was designed to assist in triaging patients and quickly identifying those who need attention by busy clinicians. It was never meant to be an assessment device. It can be used at every clinic visit or over the telephone, as the basis for a conversation with patients and to monitor fatigue progression over time.

Given this evaluation was conducted with lung cancer patients, further psychometric assessment is needed with other patient populations. It is also important to systematically introduce and evalu-

Table 5. Agreement between Fatigue Pictogram (FP) questions and subscales of the SF-36 Quality of Life Subscales for lung cancer patients

\begin{tabular}{|c|c|c|c|c|c|c|c|c|c|}
\hline \multirow[t]{2}{*}{$\begin{array}{l}\text { SF36-Quality of Life } \\
\text { Subscales }\end{array}$} & \multirow[t]{2}{*}{$\mathrm{N}$} & \multicolumn{4}{|c|}{$\begin{array}{l}R^{2} \text { Coefficients for FP-Question } 1 \\
\text { (How tired have you felt over the past week?) }\end{array}$} & \multicolumn{4}{|c|}{$\begin{array}{l}\mathrm{R}^{2} \text { Coefficients for } \mathrm{FP}-\text { Question } 2 \\
\text { (How much does feeling tired prevent } \\
\text { you from doing what you to do?) }\end{array}$} \\
\hline & & T1 & $\mathrm{T} 2$ & T3 & $\mathrm{T} 4$ & T1 & $\mathrm{T} 2$ & T3 & $\mathrm{T} 4$ \\
\hline Physical functioning & 144 & 0.34 & 0.35 & 0.31 & 0.23 & 0.39 & 0.40 & 0.41 & 0.27 \\
\hline Role-physical & 147 & 0.27 & 0.33 & 0.32 & 0.34 & 0.36 & 0.40 & 0.42 & 0.44 \\
\hline Bodily pain & 149 & 0.18 & 0.20 & 0.19 & 0.13 & 0.20 & 0.26 & 0.27 & 0.24 \\
\hline General health & 149 & 0.27 & 0.32 & 0.25 & 0.21 & 0.24 & 0.31 & 0.27 & 0.28 \\
\hline Vitality & 149 & 0.41 & 0.61 & 0.60 & 0.49 & 0.51 & 0.58 & 0.53 & 0.52 \\
\hline Social functioning & 149 & 0.33 & 0.38 & 0.32 & 0.29 & 0.40 & 0.44 & 0.44 & 0.33 \\
\hline Emotional functioning & 149 & 0.07 & 0.19 & 0.13 & 0.12 & 0.11 & 0.22 & 0.15 & 0.16 \\
\hline Mental health & 147 & 0.03 & 0.17 & 0.08 & 0.11 & 0.17 & 0.25 & 0.11 & 0.19 \\
\hline Reported health transition & 148 & 0.02 & 0.10 & 0.13 & 0.10 & 0.13 & 0.12 & 0.10 & 0.12 \\
\hline
\end{tabular}


ate the use of this tool in routine clinical practice so it can promote regular attention to fatigue by providers (Danjoux et al., 2007). This will require concerted effort, as introducing a new measurement tool often requires a change in clinical practice. The introduction of the Fatigue Pictogram as a screening device will drive the practice of fatigue management to include a deeper assessment of fatigue and tailored intervention for its relief. The evidence base for fatigue intervention is growing rapidly and has been summarized in easily understood practice guidelines for the practitioner to use (NCCN, 2007).

\section{References}

Ahlberg, K., Ekman, T., Gaston-Johansson, F., \& Mock, V. (2003). Assessment and management of cancer-related fatigue in adults. Lancet, 362(9384), 640-50.

Ancoli-Israel, S., Liu, L., Marler, M., Parker, B., Jones, B., Sadler, G., ... Fiorentino, L. (2006). Fatigue, sleep and circadian rhythms prior to chemotherapy for breast cancer. Supportive Cancer in Care, 14(3), 201-209.

Berglund, G., Bolund, C., Fornander, T., Rutqvist, L.E., \& Sjoden, P. (1991). Late effects of adjuvant chemotherapy and post operative radiotherapy on quality of life among breast cancer patients. European Journal of Cancer, 27(9), 1075-1081.

Cella, D. (1997). The Functional Assessment of Cancer Therapy Anemia (FACT-AN) Scale: A new tool for the assessment of outcomes in cancer anemia. Seminars in Haematolology, 34(3, Suppl. 2), 13-19.

Cella, D., Lai, J.S., Chang, C.H., Peterman, A., \& Slavin, M. (2002). Fatigue in cancer patients compared with fatigue in the general United States population. Cancer 94(2), 528-538.

Chan, C.W., \& Molassiotis, A. (2001). The impact of fatigue on Chinese cancer patients in Hong Kong. Supportive Care in Cancer, 9(1), 18-24.

Cleeland, C.S. (2001). Cancer-related fatigue: New directions for research (introduction). Cancer, 92(6 Suppl.), 1657-1661.

Curt, G.A., \& Johnson, P.G. (2003). Cancer fatigue: The way forward. Oncologist, 8(Suppl. 1), 27-30.

Danjoux, C., Gardner, S., \& Fitch, M.I. (2007). Prospective evaluation of fatigue during a course of curative radiotherapy for localized prostate cancer. Supportive Care in Cancer, 15(1), 1169-1176.

Davis, K.M., Lai, J., Hahn, E.A., \& Cella, D. (2008). Conducting routine fatigue assessment for use in oncology practice: Patient and provider perspective. Supportive Care in Cancer, 16(4), 379-386.

Fitch, M.I. (2010). Supportive care needs of patients with advanced disease undergoing radiotherapy for symptom control. Manuscript accepted for publication.

Fitch, M.I., \& Steele, R. (2010). Supportive care needs of individuals with lung cancer. Canadian Oncology Nursing Journal, 20(1), 15-22.

Fitch, M., Gowing, J., Murray, A., McKillop, I., Schertzer, L., \& Deane, K. (2002). Measuring supportive care needs over time: How well are we doing?" Supportive Care in Cancer, 10.

Irvine, D., Vincent, L., Grayson, J.E., Bubela, N., \& Thompson, L. (1994). The prevalence and correlates of fatigue in patients receiving treatment with chemotherapy and radiotherapy: A comparison with the fatigue experienced by healthy individuals. Cancer Nursing, 17(5), 367-378.

Mitchell, S., Beck, S.L., Hood, L.E., Moore, K., \& Tanner, E.R. (2007). Putting evidence into practice: Evidence-based interventions for fatigue during and following cancer and its treatment. Clinical Journal of Oncology Nursing, 11(1), 99-113.

National Comprehensive Cancer Network. (2007). NCCN Guidelines for Supportive Care. Retrieved from http://www.nccn.org/ professionals/physician_gls/PDF/fatigue.pdf

Nunnally, J.C., \& Bernstein, I. (1994). Psychometric theory. Toronto, ON: McGraw-Hill.

Olson, K. (2007). A new way of thinking about fatigue-A reconceptualization. Oncology Nursing Forum, 34(1), 90-93.
Given the importance patients attribute to fatigue and the virtually universal experience of this symptom, it is imperative that oncology nurses incorporate assessment and intervention regarding fatigue into their practice. This will require concerted effort on their part to access the evidence regarding effective fatigue management interventions and hone their skill in fatigue assessment. Finally, an idea for future consideration would be for patients to use the Fatigue Pictogram as a self-monitoring tool within their own self-care management approach.

Olson, K., Krawchuk, A., \& Qudussi, T. (2007). Fatigue in individuals with advanced cancer in active treatment and palliative settings. Cancer Nurse, 30(6), 1-10.

Piper, B.F. (1990). Piper fatigue scale available for clinical testing. Oncology Nursing Forum, 17(5), 661-662.

Portenoy, R.K., \& Itri, L.M. (1999). Cancer-related fatigue: Guidelines for evaluation and management. Oncologist, 4(1) 1-10.

Ream, E., Richardson, A., \& Alexander-Dann, C. (2006). Supportive intervention for fatigue in patients undergoing chemotherapy: A randomized controlled trial. Journal of Pain \& Symptom Management, 31(2), 148-61.

Servaes, P.F., Verhagen, C.F., \& Bleijenberg, G. (2002). Fatigue in cancer patients during and after treatment: Prevalence, correlates and interventions. European Journal of Cancer, 38(1), 27-43.

Smets, E.M.A., Garssen, B., Cull, A., \& deHaes, J.C.J.M. (1996). Application of the multidimensional fatigue inventory (MFI-20) in cancer patients receiving radiotherapy. British Journal of Cancer, 73(2), 241-245.

Steele, R., \& Fitch, M.I. (2008). Supportive care needs of women with gynecological cancer. Cancer Nursing, 31(4), 284-291.

Tiesinga, L.J., Dassen, T.W.N., \& Halfens, R.J.G. (1996). Fatigue-A summary of the definitions, dimensions and indicators. Nursing Diagnosis, 7(2), 51-62.

Vogelzang, N.J., Breitbart, W., Cella, D., Curt, G.A., Groopman, J.E., Herning, S.J., ... Portenoy, R.K. (1997). Patient caregiver and oncologist perspectives of cancer-related fatigue: Results of a tripartite assessment survey: The Fatigue Coalition. Seminars in Haematology, 34(3, Suppl. 2), 4-12.

Ware, J.E. Jr., \& Sherbourne, C.D. (1992). The MOS 36-item shortform health survey (SF-36). I. Conceptual framework and item selection. Medical Care, 30(6), 473-483.

Wei, J.T., Dunn, R.L., Sandler, H.M., McLaughlin, P.W. Montie, J.E., Litwin, N.S., ... Sanda, M.G. (2002). Comprehensive comparison of healthrelated quality of life after contemporary therapies for localized prostate cancer. Journal of Clinical Oncology, 20(2), 557-66.

Windsor, P.M., Nicol, K.F., \& Poller, J. (2004). A randomized controlled trial of aerobic exercise for treatment-related fatigue in men receiving radical external beam radiotherapy for localized prostate carcinoma. Cancer, 101(3), 550-57.

Winningham, M.L., Nail, L.M., Burke M.B., Brophy, L., Cimprich, B., Jones, L.S., et al. (1994). Fatigue and the cancer experience: The state of the knowledge. Oncology Nursing Forum, 21(1), 23-35.

Wu, H.S., \& McSweeney, M. (2004). Assessing fatigue in persons with cancer: An instrument development and testing study. Cancer, 10(7), 1685-95.

Yellen, S.B., Cella, D.F., Webster, K., Blendowski, C., \& Kaplan, E. (1997). Measuring fatigue and other anemia-related symptoms with the Functional Assessment of Cancer Therapy (FACT) Measurement System. Journal of Pain \& Symptom Management, 13(2), 63-74.

Zubrod, C.G., Schneiderman, M., Frei, E., Brindley, C., Gold, G.L., Snider, B., et al. (1960). Appraisal of methods for study of chemotherapy of cancer in man. Journal of Chronic Diseases, 11(1), 7-33. 